\title{
Lobbying Simulation Issues in Social Science
}

\author{
Rieko Fujita ${ }^{*} \dagger$, Tokuro Matsuo ${ }^{\star}$, \\ Tetsuya Oishi ${ }^{\S}$, Teruhisa Hochin $\mathbb{I}$
}

\begin{abstract}
In this paper we explain about lobbying and its agent-based simulations in agent field that hasn't been done in social sciences and engineering. Lobbying research is studied in political science and has been provided a lot of contributions in social science, however these are not analyzed by computational methods. Thus, we show our conducted simulation and show the process of persuading and persuasion in lobbying the interaction and the changing of opinion of group the process of persuasion at Lobbying. We analyze the process of changing of agents' thoughts and believes when they make interactions with each other in lobbying. To clarify the background in lobbying research, we introduce several existing contributions and discuss them in each research field including cultural research, organizational research, sociological research, political science research, and social psychological research, respectively.
\end{abstract}

Keywords: lobbying; persuasion; negotiation; agents; discussion; interdisciplinary study.

\section{Introduction}

Lobbying is an informal activity that the groups' destination is to achieve their aim. Lobbying is classified direct lobbying and indirect lobbying. In particular these are remarkable looked at political or economic, and business activities. In direct lobbying, lobbyists persuade to a keyperson who has authority so the things they want. Lobbyists sometimes put pressure on keypersons to agree with their intentions. So far, in the study of agent, persuasion and negotiation are studied.

In discussions, someone sometimes makes debaters' mind be affected, influenced, and changed. Lobbying is one of ways to change their mind before/after discussions [1][2]. Lobbying is able to 1) make person have an opinion, and 2) change the person's mind to opposite. For example, we can find easily this kind of situations in president elections in the United States.

\footnotetext{
* Advanced Institute of Industrial Technology, Tokyo, Japan

$\dagger$ Kyoto Institute of Technology, Kyoto, Japan

\# Advanced Institute of Industrial Technology, Tokyo, Japan

$\S$ Advanced Institute of Industrial Technology, Tokyo, Japan

II Kyoto Institute of Technology, Kyoto, Japan
} 
Agent technologies will enable to realize automated discussion in the future [3]. In agent-based discussion support system, people's mind are needed to be understood by the computers. There are a lot of works in agent-based-negotiation technologies. Agent-based electronic commerce is well-known on automatic monetary negotiations. Also known about double-auction-based negotiation if agents have a certain utilities and payoffs .

In this paper we explain about lobbying that has not been mentioned in agent technology and discuss it from the point of view of social sciences and engineering. Lobbying research is studied in political science and has been provided a lot of contributions in the United States. On the other hand, seldom works have discussed about it with engineering approaches from the view point of negotiation between players. Lobbying is one of the phenomenon on negotiation interaction. In lobbying, there are two activities, such as persuading and persuasion. In this paper we show our conducted simulation, and show the process of persuading and persuasion in lobbying the interaction and the changing of opinion of group the process of persuasion at Lobbying. We analyze the process of changing of agents' thoughts and believes when they make interactions with each other in lobbying. In the simulation each lobbyist persuades his/her antagonists and peers about his/her thoughts. An ability to negotiate others is defined. Persuaded agent's thought changes based on his/her ability of acceptance of persuasion. When an antagonist is persuaded by the agent, the degree of his/her thought of degree of opposing view are weakened. When an agent is communicated by his/her peer, his/her degree of supporting his/her believes is strengthen. Thus, these processes decrease/increase each group's solidarity. The model shown in this paper is supposed the power of persuasion and the weakness of mind about persuasion.

This paper consists of the following five sections. In Section 2, we show the definitions about the terms referring to the existing contributions and discuss needs of our conducted simulation. Then, definitions, assumptions, and conditions of our model are shown and preliminary simulations are conducted by using them in Section 3. After that, we give, in Section 4, some discussions on perspectives of our research from several point of view. Finally, we conclude this paper by summarizing our research in Section 5.

\section{Preliminary Consideration}

In this section, we define terms related with research field of lobbying, and give preliminary discussion concerned with the research. In lobbying, multiple players play active roles to persuade and negotiate as lobbyists [5]. Lobbyists normally belong to organizations, such as business firms as lobbyists or general companies and nonprofit organizations. The business firm's lobbyist is a specialist of lobbying and outsourced to lobby from his/her client like a company. He/she works to increase the client's benefit. On the other hand, the lobbyist who belongs a certain organization concentrates on lobbying not only to pursue their organization but also to achieve request to make a profit. And we should not forget the existences that are lobbied, such as a keyperson on political decision.

\subsection{Interest Group and Associational Interest Group}

In this paper we define Interest Group as "a group of people with common interests" [6]. And if it works for their realization of profits, it's called "pressure group". Pressure groups sometimes propose their opinions to a political party and the government, and persuade into agreement with the opinion for their profits. Tsujinaka pointed out, in his published 
contribution in 1988, "Interest groups or interest associations are the exactly 'real' that is necessary for democracy in industrialized countries including liberty and participation". And generally they are studied at political science in Japan [7]. The reason why they study in political science is pressure groups that act to politics. They have not been established disorder, but to protect their- company, meister, people's profit. In other words, lobbying is in very important position at the place of social activities like economic activity. Economic activity hardly cannot be detached politics in democratic regime because the are profitably related with political decisions.

\subsection{Lobbying}

When one group persuades another, it has economic or social motivation to earn profits. This kind of group is called an interest group. In the previous section, we mentioned a further associational interest group when the interest group visibly does such behavior. A pressure group does persuasion activity with pressure. That pressure group is called a lobby. Persuading done by a pressure group to gain profit is called lobbying. The person who makes a pressure to someone is called a lobbyist. The reason why the pressure group is called a lobbyist is that the 18th President Grant in the United States had been tried to be persuaded at the lobby of the hotel. The United States has the federal lobbying regulation law (1947 establishment) and permits a registering lobbyists by law. After registered, they can work as lobbyists at the federal/ region government or court. In Japan, people don't have a good impression about lobbying, and Japanese language has a negative images to lobbyists. This is not limited in Japanese, but also European language. It is not general of working to justice in Japan and Europe [9].

\subsection{Motivation}

As mentioned in Section 2.2, are totally different the creation and recognition of lobbying between the United States, Europe, and Japan. It is important to compare and consider these countries and regions. Lobbying, from a micro viewpoint, is communication between players, so that it is able to understand more if we analyze the interaction and compare phenomenon in lobbying as whole. In this paper we focuses on the example of simulation about lobbying between players. In the simulation it is assumed that there are two sides both persuading agents and persuasion agents. And also, each player has different ability for persuading and persuasion.

Table 1: Initial value of belief, ability and capability

\begin{tabular}{c|c|c|c|c}
\hline Agent & $\begin{array}{c}\text { Value of } \\
\text { favor } \\
\text { about } \\
\text { decision 1 }\end{array}$ & $\begin{array}{c}\text { Value of } \\
\text { favor } \\
\text { about } \\
\text { decision 2 }\end{array}$ & $\begin{array}{c}\text { Ability of } \\
\text { persuasion }\end{array}$ & $\begin{array}{c}\text { Capability } \\
\text { of } \\
\text { acceptance }\end{array}$ \\
\hline \hline$a_{1}$ & 10 & 3 & 3 & 2 \\
\hline$a_{2}$ & 7 & 10 & 2 & 4 \\
\hline
\end{tabular}


Table 2: Value of belief in the example

\begin{tabular}{c|c|c}
\hline Round & $\begin{array}{c}\text { Value of favor } \\
\text { about decision 1 }\end{array}$ & $\begin{array}{c}\text { Value of favor } \\
\text { about decision 2 }\end{array}$ \\
\hline \hline Initial & 7 & 10 \\
\hline First round & 10 & 7 \\
\hline Second round & 13 & 4 \\
\hline
\end{tabular}

Table 3: Value of belief in the simulation

\begin{tabular}{c|c|c}
\hline Agent & D1 & D2 \\
\hline \hline A1 & 70 & 30 \\
\hline A2 & 60 & 40 \\
\hline A3 & 30 & 70 \\
\hline A4 & 20 & 80 \\
\hline
\end{tabular}

\section{Simulation}

In this section, we give some definitions and assumptions about agents' properties to be used in our simulation.

\subsection{Definitions}

- Agent $a_{i}$ is the $i$ th agent in agent set $A=\left\{a_{1}, \ldots, a_{i}, \ldots, a_{k}\right\}$.

- Each agent has a strength of favor bout candidate of decision and the strength may be changed by persuasion.

- Agent has opportunities to persuade agents who belong forces of opposition.

- Set of candidate of decisions is shown as $D=\{1, \ldots, j\}$.

- Number of round of persuasion is finite and its set is $T=\{0, \ldots, s, \ldots, t\}$. For example, when $s=5$, it is 5th round of persuasion. Strength of favor of agent $a_{i}$ is shown as $a_{i, 5,\{1, \ldots, j\}}$.

- Each agent has an ability of persuasion and $p_{i}$ is agent $a_{i}$ 's ability.

- Each agent has a capability of acceptance from persuasion and $q_{i}$ is agent $a_{i}$ 's capability.

- Agent $a_{i}$ 's strength of favor about decision and his/her property is shown as $a_{i, s,\{1, \ldots, j\}, p, q}$ after round $s$.

\subsection{Assumptions}

We give some assumptions about property of agents in our agent simulations, and set a situation of our research.

- In lobbying, agents sometimes affect other's thinking and decision through persuasion. 
- Agents are sometimes affected through persuasion by others as well.

- No agent persuades and affects his/her opining and thinking for himself/herself.

- When an agent $a_{i}$ affect his/her opining to an agent $a_{i+1}$, we assume the following rules.

- If $p_{i}>q_{i+1}$, the influence is $q_{i+1}$. When agent $a_{i+1}$ has opposite view of decision from agent $a_{i}$, value of his favor of his supported decision reduces $q_{i+1}$ and value of his favor of his unsupported decision increases $q_{i+1}$. If agent $a_{i+1}$ has same view of decision from agent $a_{i}$, value of his favor of his unsupported decision reduces $q_{i+1}$ and value of his favor of his supported decision increases $q_{i+1}$.

- If $p_{i}<q_{i+1}$, the influence is $p_{i}$. The rule of change of value is employed same rule as above noticed.

Table 4: Condition and situation

\begin{tabular}{l|l}
\hline Exp. 1 & $\begin{array}{l}\text { Each agent has small strength of } \\
\text { both persuasion and acceptance. }\end{array}$ \\
\hline Exp. 2 & $\begin{array}{l}\text { Each agent has middle strength of } \\
\text { both persuasion and acceptance. }\end{array}$ \\
\hline Exp. 3 & Random. \\
\hline Exp. 4 & $\begin{array}{l}\text { Strength of persuasion of one group is } \\
\text { middle. }\end{array}$ \\
\hline Exp. 5 & $\begin{array}{l}\text { Some agents have large strength of } \\
\text { persuasion. }\end{array}$ \\
\hline Exp. 6 & $\begin{array}{l}\text { Strength of acceptance of one group is } \\
\text { large. }\end{array}$ \\
\hline Exp. 7 & $\begin{array}{l}\text { Some agents have large strength of } \\
\text { acceptance. }\end{array}$ \\
\hline Exp. 8 & $\begin{array}{l}\text { Agents in one group has large strength } \\
\text { of persuasion. }\end{array}$ \\
\hline
\end{tabular}

\subsection{Example}

We consider where two agents $a_{1}$ and $a_{2}$ at the lobby. There are two views of decision. Each agent has ability of persuasion and capability of acceptance shown in the Table 1 . In lobbying, when agent a1 affects to agent $a_{2}$, the value where agent $a_{2}$ 's favor is changed is 3 . Since agent $a_{1}$ support the decision 1 , the $a_{2}$ 's value of decision 1 is increased 3 and $a_{2}$ 's value of decision 2 is decreased 3. Table 2 shows the agent $a_{2}$ 's value of favor about decision in first and second rounds.

\subsection{Experiment}

This section shows the result of simulation when the number of rounds is 100 and number of agents is 4. There are two candidate of decisions and each agent has the value of favor about decision as shown in Table 3. We conducted simulations in eight cases of set of ability and capability shown in Table 4 . Table 5 shows the value of ability of persuasion 
Table 5: Data set

\begin{tabular}{|c|c|c|c|c|c|c|c|c|c|c|c|c|c|c|c|c|}
\hline & & & \\
\hline Agent & \multicolumn{2}{|c|}{ Exp. 1} & \multicolumn{2}{|c|}{ Exp. 2} & \multicolumn{2}{|c|}{ Exp. 3} & \multicolumn{2}{|c|}{ Exp. 4} & \multicolumn{2}{|c|}{ Exp. 5} & \multicolumn{2}{|c|}{ Exp. 6} & \multicolumn{2}{|c|}{ Exp. 7} & \multicolumn{2}{|c|}{ Exp. 8} \\
\hline$a_{1}$ & 0.5 & 0.5 & 2.0 & 2.0 & 2.5 & 2.0 & 1.5 & 0.5 & 3.0 & 1.0 & 1.5 & 3.0 & 2.0 & 2.0 & 3.0 & 3.0 \\
\hline$a_{2}$ & 0.5 & 0.5 & 2.0 & 2.0 & 1.0 & 2.5 & 1.5 & 0.5 & 1.0 & 2.0 & 1.0 & 3.0 & 2.5 & 3.0 & 3.0 & 3.0 \\
\hline$a_{3}$ & 0.5 & 0.5 & 2.0 & 2.0 & 1.5 & 1.0 & 0.5 & 1.5 & 3.0 & 3.0 & 2.0 & 1.0 & 1.0 & 3.0 & 1.0 & 1.0 \\
\hline$a_{4}$ & 0.5 & 0.5 & 2.0 & 2.0 & 3.0 & 2.0 & 0.5 & 1.5 & 1.0 & 2.0 & 0.5 & 1.0 & 3.0 & 2.0 & 1.0 & 1.0 \\
\hline
\end{tabular}

\begin{tabular}{|c|c|c|c|}
\hline$\frac{}{{ }_{50}} \frac{}{\cdots-1}$ & 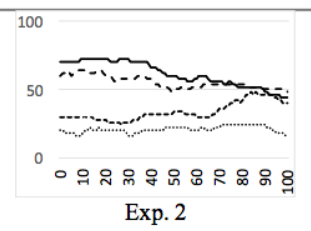 & 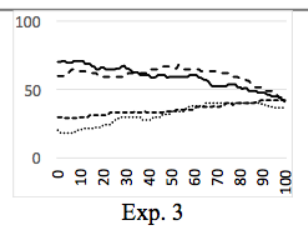 & 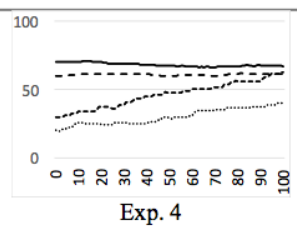 \\
\hline 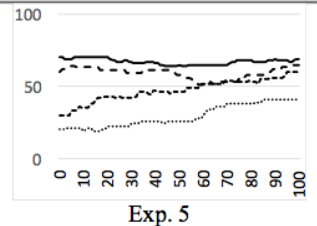 & 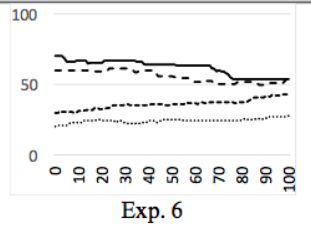 & 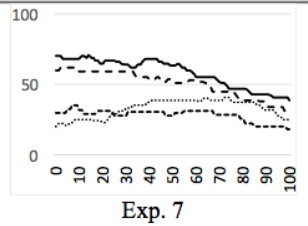 & 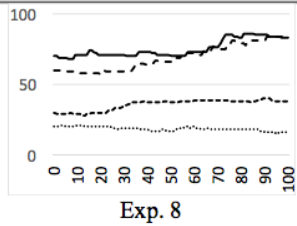 \\
\hline
\end{tabular}

Figure 1: Changes of Values of Belief of Agent

and capability of acceptance in each case. Fig. 1 shows the result of simulations using these set, respectively. The results of simulations are shown as line chart. The horizontal axis shows round of persuasion and the vertical axis shows the strength of favor about decision. The value between 50 to 100 indicates the decision 1 and the value between 0 to 50 indicates the decision 2. In each step, one persuading agent and one persuaded agent is randomly chosen. Persuading agent persuades to change the persuaded agent's mind. Value of supported view of persuaded agent is changed.

\section{Discussion}

\subsection{Cultural Perspectives}

There are a lot of contributions in Japanese culture or adjacent study. However they do not mainly contain comparison of and thought about lobbying with the United States and Japan. Existing work [10][11] are classified differences of communications in Japan and the United States. Referring the contributions, we show eight types of differences in following Table 6.

Therefore, in lobbying, the way or achievement is different between two countries. These differences are not caused from only cultural aspects, but also organization that lobbyists belong to. Lobbying is generally studied in political science, and many of them are done in the United States. To find a successful contribution in Japan as well as in the United States, we first detect and analyze a key factor from successful cases and unsuccessful ones in lobbying. Further, these cases are broken these cases down into patterns comparing between Japanese personality and American personality. And we can know, to make a successful lobbying for Japanese lobbyists, what is (are) lack of the elements in Japanese lobbying. 
Table 6: Differences between Japanese and American

\begin{tabular}{c|l|l}
\hline & Japan & United States \\
\hline \hline 1 & $\begin{array}{l}\text { Human related } \\
\text { communication }\end{array}$ & $\begin{array}{l}\text { Business } \\
\text { communication }\end{array}$ \\
\hline 2 & $\begin{array}{l}\text { Accommodative } \\
\text { communication }\end{array}$ & $\begin{array}{l}\text { Non-accommodative } \\
\text { communication }\end{array}$ \\
\hline 3 & $\begin{array}{l}\text { Strategical-emotional } \\
\text { communication }\end{array}$ & $\begin{array}{l}\text { Logical } \\
\text { communication }\end{array}$ \\
\hline 4 & $\begin{array}{l}\text { Group } \\
\text { communication }\end{array}$ & $\begin{array}{l}\text { Individual } \\
\text { communication }\end{array}$ \\
\hline 5 & $\begin{array}{l}\text { Careful-measured } \\
\text { communication }\end{array}$ & $\begin{array}{l}\text { Predictable } \\
\text { communication }\end{array}$ \\
\hline 6 & $\begin{array}{l}\text { Non critical } \\
\text { communication }\end{array}$ & $\begin{array}{l}\text { Critical } \\
\text { communication }\end{array}$ \\
\hline 7 & $\begin{array}{l}\text { Modest } \\
\text { communication }\end{array}$ & $\begin{array}{l}\text { Positive } \\
\text { communication }\end{array}$ \\
\hline 8 & $\begin{array}{l}\text { Saving-face } \\
\text { communication }\end{array}$ & $\begin{array}{l}\text { Straightforward } \\
\text { communication }\end{array}$ \\
\hline
\end{tabular}

\subsection{Organizational Perspectives}

Because organizations' culture and types are different between countries, lobbyists' perceptions, thought, behavior, and business style are different between countries. We can find more concrete differences by analyzing the position, at which lobbyists as the keypersons in the organizations do own job. From such point of view, there are two kinds of effects; lobbyists to organizations, and organizations to lobbyists. It is not difficult to imagine where Japanese cultural organizations have some obstructive factors not to make a successful lobbying. Lobbyists, in the organizations, are the special keypersons to continue their business. It is not inferred that the lobbyists in Japan can work well with their free description from the structure of organization. Finding out concrete reasons, conditions, and situations where Japanese lobbying is weaker than other countries, the appropriate behavior for lobbyists will be clarified.

\subsection{Sociology Perspectives}

In social science, there are several studies in experimental sociology. They, however, do not provide a knowledge about lobbying by computer simulation. It will be able to enhance the reliability of study by using computer simulation, as well as using case-study and literature research. Result of computer simulation provides a set of candidates of desirable situations by designed models and initial values. For example it is said using catchphrases, though not to clarify how many times they are used. Computer simulation is conducted with numerical and quantitative values, the set of results is obtained with each number of catchphrases. To get quantitative datas- conditions, situations, and frequency, we can get the rules of actual conditions of difference of lobbying between Japanese and Americans. 


\subsection{Political Science Perspectives}

The studies on lobbying in political science are known as comparison and linguistics [7][8]. The former is the research related with foreign lobbying study. The latter is the research related with communication effects on linguistic issues on persuasion and persuading. Also there are several existing work about American lobbying[14][15][16]. They mainly study strategies, case studies, and history of lobbying. On the other hand, there is not a plenty number of contributions about what kind of behavior leads successful result and unsuccessful outcome in details.

\subsection{Social Psychological Perspectives}

Social psychological discussion is needed to analyze lobbying on cultural, organizational perspective, sociology, and political science in more detail. Social psychology is the one of the research fields to analyze the human interaction and effects with each other how the members of society and organization commit their society. Agent simulations provide some knowledge about influence between a lobbyist and organizations as described in Section 4.2. Existing works have been done by the survey through questionnaire and interview. On the other hands, using computer simulation can not be found in lobbying analysis. In agent-based simulations, an agent is modeled as one of members in an organization, which is affected by other members and the organization in itself. It focuses on remuneration and punishment to the lobbyist from the organizations and other members, when the lobbyist works well or not. If the organization is evaluated from society about their behavior and decision, the condition and situation of simulation of the lobbying are needed to be added. In social psychology, human relationships and its dynamics in organization can be analyzed. Also, small groups like a faction in organization can be analyzed by focusing on their interests. Many patterns and cases projecting phenomenon in agent simulation provide a good suggestions to social psychological research.

\section{Conclusion}

This paper explained lobbying in the agent field that has not been done in social sciences and engineering. These studies were focused on history, concession, and influences on groups, and published as a lot of contributions in the United States. Fishkin in 2011 [17], pointed out that people may change their voting intention by the person who has big influence and mind of groups. That can be interpreted as "invisible-lobbying". It is neither a good number of existing work of analysis of lobbying on social sciences today. Moreover, there are not a lot of contributions on negotiation technology between players in the engineering research field. Lobbying is one of the phenomena about negotiation interaction between players both persuading and persuasion. The lobbies-pressure group can get their profits. Our future research includes to analyze an interaction between a lobbyist and his/her organization based on social psychological approach.

\section{Acknowledgements}

This work was partially supported by CREST, JST. 


\section{References}

[1] David Austen-Smith and John R. Wright, "Counteractive Lobbying", American Journal of Political Science, Vol. 38, No. 1, 1994, pp. 25-44.

[2] David Austen-Smith, "Information and Influence: Lobbying for Agendas and Votes", American Journal of Political Science, Vol. 37, No. 3, 1993, pp. 799-833.

[3] Michael J. Wooldridge, "Agent Technology: Foundations, Applications, and Markets", Springer. 1998.

[4] R.Preston McAfee, "A dominant strategy double auction", Journal of Economic Theory, Volume 56, Issue 2, pp.434-450, April 1992.

[5] O Cadoft, J de Melot, M Olarreaga, "Lobbying and the Structure of Protection", Institut d'Economie et Economtrie, Universit de Genve, 1996. (Discussion paper.)

[6] Ikuo Kume, et al., "Politics", Yuhikaku Publisher, 2003. (in Japanese)

[7] Yutaka Tsujinaka, "Interest Group", University of Tokyo Press, 1988. (in Japanese)

[8] Yutaka Tsujinaka (Eds.), "Civil Society Organizations and Interest Groups in Current Japan”, Bokutaku-Sha, 2002. (in Japanese)

[9] Klemens Joos, Franz Waldenberger, "Successful Lobbying in the New Europe", Berliner Wissenschafts-Verlag, 2004.

[10] Tao Lu, "Japanese-Chinese Business Communication Research in Japan", Management Research, Vol.8, pp.43-56, 2008. (in Japanese)

[11] Ikushi Yamaguchi, "Strategy of Cross-cultural Motivational Communication Processes for Workers”, Dobunkan Publisher, 1998. (in Japanese)

[12] Yamagishi, T., et al. "The social exchange heuristic: Managing errors in social exchange", Rationality and Society. Vol.19, No.3, pp.259-291, 2007.

[13] Hitomi Yokoyama, Ikuo Daibo, "A study of Interpersonal Communication Channels in Face-to-Face Persuasion: Channel Use and Effects", Journal of Japanese Association of the Sociolinguistic Sciences, Vol.15, pp.73-88, 2012. (in Japanese)

[14] Godwin, Ken., et al., "Lobbying and policymaking: the public pursuit of private interests", SAGE Publications Inc., Thousand Oaks, USA, 2013.

[15] Holyoke, Thomas T., "Interest groups and lobbying: pursuing political interests in America”, Westview Press, Boulder, USA, 2014.

[16] Avner, marcia., et al., "The lobbying and advocacy handbook for nonprofit organizations: shaping public policy at the state and local level", Fieldstone Alliance, New York, USA, 2013.

[17] James S. Fishkin, "When the people speak: deliberative democracy and public consultation", Oxford University Press, 2009. 